\title{
Feasibility study of gasification of oil palm fronds
}

\author{
S.A. Sulaiman ${ }^{1 *}$, S. Balamohan ${ }^{2}$, M.N.Z. Moni ${ }^{1}$, S.M. Atnaw ${ }^{3}$ and A.O. Mohamed ${ }^{4}$ \\ ${ }^{1}$ Department of Mechanical Engineering, Universiti Teknologi PETRONAS, \\ 36210 Bandar Seri Iskandar, Perak, Malaysia \\ *Email: shaharin@petronas.com.my \\ Phone: +6053687013 \\ ${ }^{2}$ Reliability and Integrity Engineering Department, PETRONAS Carigali Sdn. Bhd, \\ Miri, Sarawak, Malaysia \\ ${ }^{3}$ Faculty of Engineering Technology, Universiti Malaysia Pahang, \\ Lebuhraya Tun Razak, 26300 Pahang, Malaysia \\ ${ }^{4}$ Faurecia Emission Control Technologies, 2301 Commerce Center Dr, \\ Franklin, Ohio 45005, USA
}

\begin{abstract}
Considering the large and consistent supply, oil palm fronds could be a promising source of biomass energy through gasification. There is very scarce information on the characteristics of oil palm fronds, which is vital in deciding if such biomass is technically suitable for gasification. In the present work, the feasibility of oil palm fronds for biomass gasification is studied. The study is conducted experimentally via standard tests to determine their thermochemical characteristics. Ultimate analysis is conducted to determine the contents of carbon, nitrogen, hydrogen and sulphide in oil palm fronds. Proximate analysis is performed to identify the burning characteristics of the biomass. The energy content in the fronds is determined by using a bomb calorie meter and is around $18 \mathrm{MJ} / \mathrm{kg}$. The ignitability of the fronds is also studied experimentally to assess the ease to start-up combustion of the fronds. The characteristics of the flame of the resulting syngas from gasification of oil palm fronds are qualitatively studied. Simulated syngas composition study reveals potentials of $22 \% \mathrm{CO}, 1.3 \% \mathrm{H}_{2}, 18.5 \% \mathrm{CO}_{2}$ and traces of $\mathrm{CH}_{4}$. The study is extended to computer simulation to predict composition of the syngas. It is found from this work that oil palm fronds are feasible for gasification and has a good potential as a renewable energy source.
\end{abstract}

Keywords: Gasification; biomass; solid fuel; syngas; combustion; energy.

\section{INTRODUCTION}

Malaysia is one of the major planters of oil palm trees in the world. As the main exporter of palm oil, the country has significantly large plantation areas. There are more than 4.5 million hectares of oil palm plantations in Malaysia [1, 2]. Nearly all of the parts of oil palm trees, as shown in Figure 1, are commercially utilized, mainly in energy and manufacturing sectors. Nevertheless, oil palm fronds (OPF) have very limited usage. Oil palm trees are pruned during the harvesting of fresh fruit bunches for the production of oil. The fronds are pruned regularly but have little use and are mainly left on the ground in a huge quantity for the slow process of natural decomposition. In 2003, it was estimated that 36 million tonnes of pruned fronds were produced [3], with an average rate of 24 pieces per year from every oil palm tree. Although Chan et al. [4] gave a lower 
estimate, i.e. $82.5 \mathrm{~kg}$ of fronds $/$ palm/year, such data was provided more than 30 years ago at which the maintenance approach of the plantation was different. From another point of view of findings, for every tonne of palm oil produced from fresh fruit bunches, a farmer harvests around 6 tonnes of waste palm fronds. Figure 2 shows illustration of an OPF. It mainly consists of the hard and fibrous petiole and the leaflets. The average bulk density of OPF was reported to be about $700 \mathrm{~kg} / \mathrm{m}^{3}$ and the weight of each frond was between 15 and $20 \mathrm{~kg}$ depending in the age of the palm tree [5]. From the same source of information, the dry matter weight ratio of petiole to leaflets (including the rachis) was approximated to be 1.5 , and the water content in fresh leaflets and petioles were in the range of $54-56$ $\%$ and $75-79 \%$, respectively.

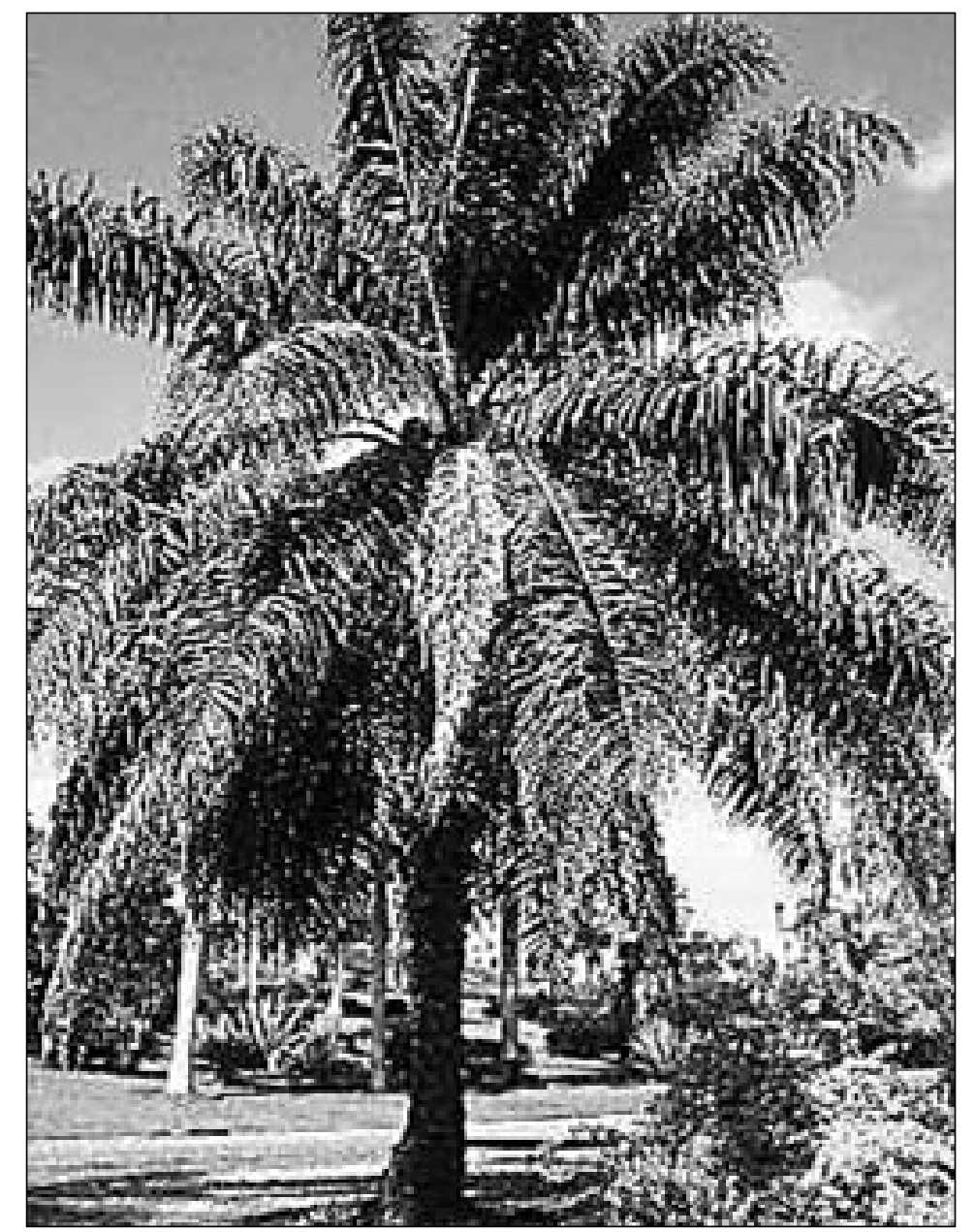

Figure 1. Oil palm tree.

OPF are usually left on the ground between palm trees in a huge quantity to naturally decompose for soil conservation, erosion control and nutrient recycling [6]. Nevertheless, it takes a long time for the fronds to degrade, and thus planters are required to dispose them properly in order to avoid mobilization problems within plantations. A practical use of the fronds is as roughage feed for ruminants [6] although this is presently done in small quantity. When dry, the OPF physically resemble wood or rice husks such that it may be suitable for biomass gasification. Considering its large and consistent supply, oil palm fronds could be a promising source for biomass energy. With the present global concerns on the escalating price and depleting sources of fossil fuels against the 
sharply rising demands $[7,8]$ as well as the alarming environmental issues, particularly on the greenhouse gas effect [9], the use of OPF for biomass gasification in the near future may alleviate those problems. Gasification of biomass for fuels has been adopted in many developed and developing countries in various scales in response to the current energy and environmental crises, and also as an alternative to replace coal as a conventional gasification fuel [10]. Biomass gasification and co-gasification is a clean energy and a promising fuel alternative [11-15]. At present, biomass sources are mainly in the form of agricultural and domestic wastes [16-19]. The consumption of biomass energy is still small. This could partly be due to the availability and readiness of the biomass sources [20]. However, in some parts of the world, biomass firing and gasification have recently gained interests in the field of research and real applications in various scales [21-24]. Only a relatively small number of research projects have been initiated on biomass combustions in this country [25-29], while only several more focused on OPF [5, 30-37]. Literature review revealed that OPF may be one of the least studied parts of an oil palm tree, while other researches focused on mostly the derivative wastes of oil palm fruit such as empty fruit bunches, palm kernel shell, palm mesocarp fiber and palm oil mill effluent [38-42]. The objectives of this study were to inspect the suitability of OPF as a biomass solid fuel for gasification to generate heat and power. Several preliminary tests were carried out including fuel thermochemical tests, computer simulation tests and actual gasification.

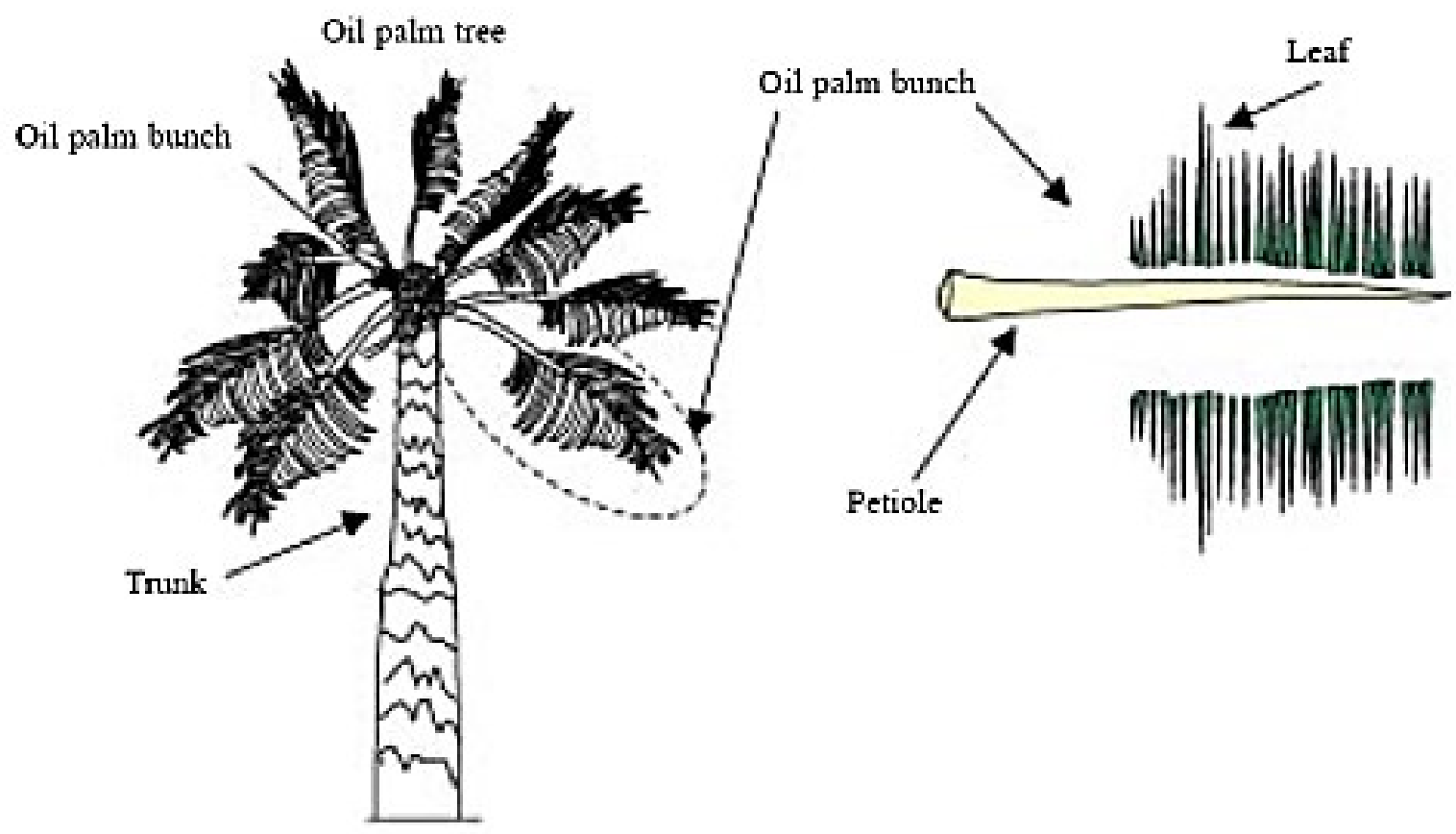

Figure 2. Oil palm frond [2].

\section{EXPERIMENTAL SETUP}

The pruned OPF were collected from a plantation area and were dried naturally under the sun for 3 days. They were then further dried in an oven at $55^{\circ} \mathrm{C}$ for a period of 24 hours. The OPF were ground into fine powder using a granulator. Ultimate Analysis of the powdered OPF was conducted by using the Leco CHNS-932 analyzer in accordance with 
ASTM D3176-89(2002) [39] to determine its carbon, hydrogen, nitrogen, and sulphur content. Thermo-Gravimetric Analysis (TGA) or the Proximate Analysis of the sample was performed to express the burning characteristics of the biomass, comprising fixed carbon, ash, moisture and volatiles. This was performed by using the Perkin Elmer TGA7 Analyzer with PYRIS 2003 software. The tests were conducted in accordance to ASTM E 1131-98, Standard Test Method for Compositional Analysis by Thermogravimetry [40]. The average weight of the OPF sample for the test was $12.03 \mathrm{mg}$. The operating temperature range of the TGA was from room temperature to $900^{\circ} \mathrm{C}$ with an accuracy of $\pm 2^{\circ} \mathrm{C}$.

The calorific value of the OPF was determined using a LECO AC-350 bomb calorimeter. The calorific test was done in accordance to ASTM D 5865-07, Standard Test Method for Gross Calorific Value of Coal and Coke [41]. The calorific value of a biomass fuel is critical in choosing an appropriate technology for energy conversion. In the measurements, the gross calorific value of the specimen is defined as the heat released by a complete combustion of a unit quantity, at a constant volume, in an oxygen bomb calorimeter under standard condition. A set of five measurements were conducted for each of the Ultimate Analysis and the calorific value tests. Three measurements were conducted for each of the Proximate Analysis test. The values were averaged and the standard deviations were obtained. To assess the ignitability of OPF at the start-up of its gasification operation, a test was conducted in a custom made burning cylindrical chamber of $300 \mathrm{~mm}$ diameter and $600 \mathrm{~mm}$ high. OPF petiole of 100, 200 and $300 \mathrm{~mm}$ length and cross sectional area of about $700 \mathrm{~mm}^{2}$ were dried in an oven at $100^{\circ} \mathrm{C}$ for 12 hours. The leaflet was not detached from the petiole. The ignition was assisted with petrol of between 1 to $10 \mathrm{ml}$ in volume. The effect of air motion was also studied by running a propeller fan at the top of the chamber at $0,50,100$ and $150 \mathrm{rpm}$. The time to completely burn the OPF was recorded.

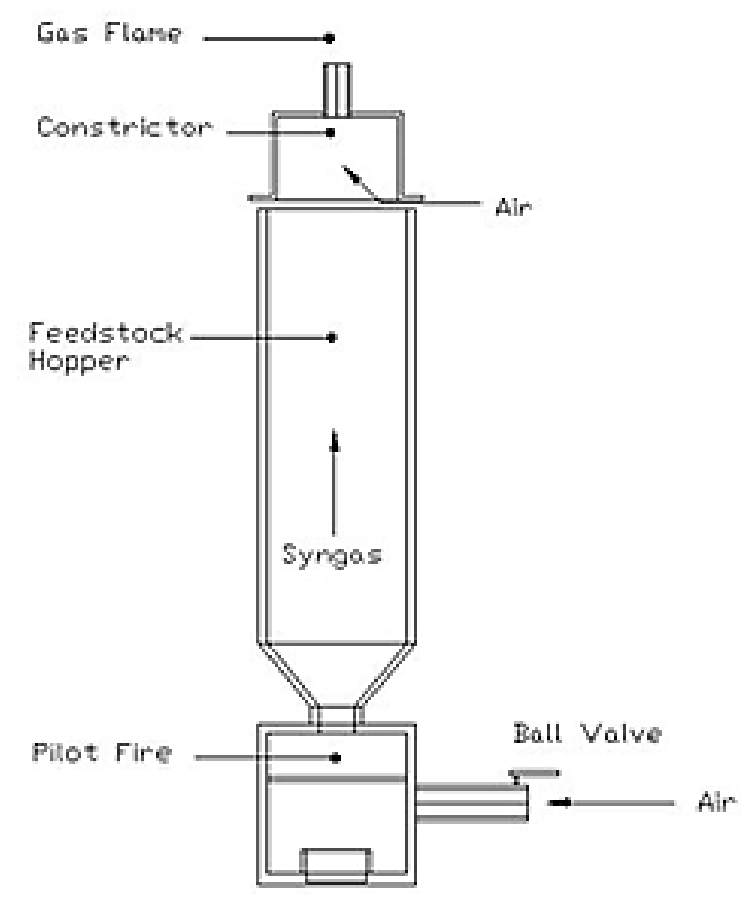

Figure 3. Schematic of the bench top updraft gasifier. 
A qualitative study on the resulting flame of the OPF syngas was conducted using a small gasifier with an internal dimension of $200 \mathrm{~mm} \times 200 \mathrm{~mm} \times 1000 \mathrm{~mm}(\mathrm{H})$, as shown in Figure 3. The purpose of this experiment was to assess the ease of handling OPF for gasification and the quality of its flame. The gasifier was set on a natural updraft arrangement where air was drawn into the set from an inlet pipe at the bottom of the unit from pressure difference driven by the ongoing combustion inside. Dry wood was used to initiate the pilot fire and later OPF was used as the main feedstock. The amount of air supply was controlled using a ball valve located at the air inlet pipe. A stainless steel constrictor was positioned on top of the gasifier, with a small gap in between the two, to allow air to enter and mix with the producer gas.

\section{PREDICTION OF SYNGAS COMPOSITION}

To predict composition of the produced gas from gasification of OPF, equilibrium modelling was conducted using ASPEN PLUS and also another program that was developed by Fock et al. [42]. Results of the modelling study could be used to identifydesign and operating parameters of the gasification system. ASPEN or Advanced System for Process Engineering is a software package that employs different thermodynamic models including the equilibrium and kinetic rate models. The ultimate analysis of the OPF was used as the input to estimate the composition of the syngas. The combustion and reduction zones of gasification were modelled using Gibbs reactor model, assuming equilibrium reaction. Calculation of the heat and mass balances of a solid process required a physical properties model suitable for solid components [36]. Detailed elaboration of the models used in the present work can be found in the references $[36,43]$. The other program, which was obtained from Fock et al. [42], was built in an equation solver program "Engineering Equation Solver" [44], which was made up of a series of modules each containing one process. The fundamental equations in the model were conservation of mass and energy. The same input used in the ASPEN PLUS model was used in this model. The gas composition from the gasification chamber was determined based on equations for element balances and the water gas shift equation, a temperature dependent equation for chemical equilibrium between hydrogen, carbon dioxide, carbon monoxide and water (gas phase). In both simulations, the OPF was formulated as $\mathrm{CH}_{1.55} \mathrm{O}_{0.88}$. The ambient temperature was set as $25^{\circ} \mathrm{C}$ and the feedstock mass flow rate was assumed to be $20 \mathrm{~kg}$ per hour. The OPF moisture content was assumed to be $10 \%$.

\section{RESULTS AND DISCUSSION}

The results of this work comprise of both experimental and simulation studies. The experiments include the thermochemical, ignition and flame tests. The simulation study was limited to prediction of the syngas composition.

\section{Thermochemical Tests}

The chemical composition of the OPF determines its suitability for gasification. For instance, high carbon content would be desired as it is an important element in the fuel for the gasification process. A low content of sulphur would be desirable, as its emission could react with water, oxygen and oxidants to form acidic compound such as acid rain. 


\section{Ultimate Analysis}

Table 1 shows the average measured composition of carbon, hydrogen, nitrogen, and sulphur for each of the tests on the fine dry powder of oil palm fronds, in weight percentage on dry basis, obtained from the ultimate analysis. Also shown in Table 1 are the standard deviations of the measured data. It is obvious that the tests were highly repeatable as indicated by the low standard deviation of each element. It is shown in Table 1 that the carbon content $(42.65 \%)$ of the oil palm frond sample is moderate, and comparable to other types of biomass such as corn stalk and wheat straw [45]. The H:C and $\mathrm{O}: \mathrm{C}$ ratios are 0.13 and 1.16, respectively. Also shown in Table 1 are the contents of Nitrogen and Sulphur, which are low. The Sulphur content is lower than in fossil fuels [46], with the exception of unleaded gasoline, and thus would minimize negative effects on the environment. A comparison of the average carbon content with other types of biomass feed [47-49] revealed that OPF has reasonably high carbon content, and hence could be considered as competitive with other biomass sources as solid fuel for gasification and co-firing [2].

Table 1. Chemical composition of OPF as measured using the ultimate analysis test.

\begin{tabular}{ccccc}
\hline & \multicolumn{4}{c}{ Composition (wt. \%) } \\
\hline Element & Carbon, C & Hydrogen, H & Nitrogen, N & Sulphur, S \\
\hline Average & 42.65 & 5.48 & 2.18 & 0.11 \\
\hline Std. Dev & 0.44 & 0.25 & 0.05 & 0.01 \\
\hline
\end{tabular}

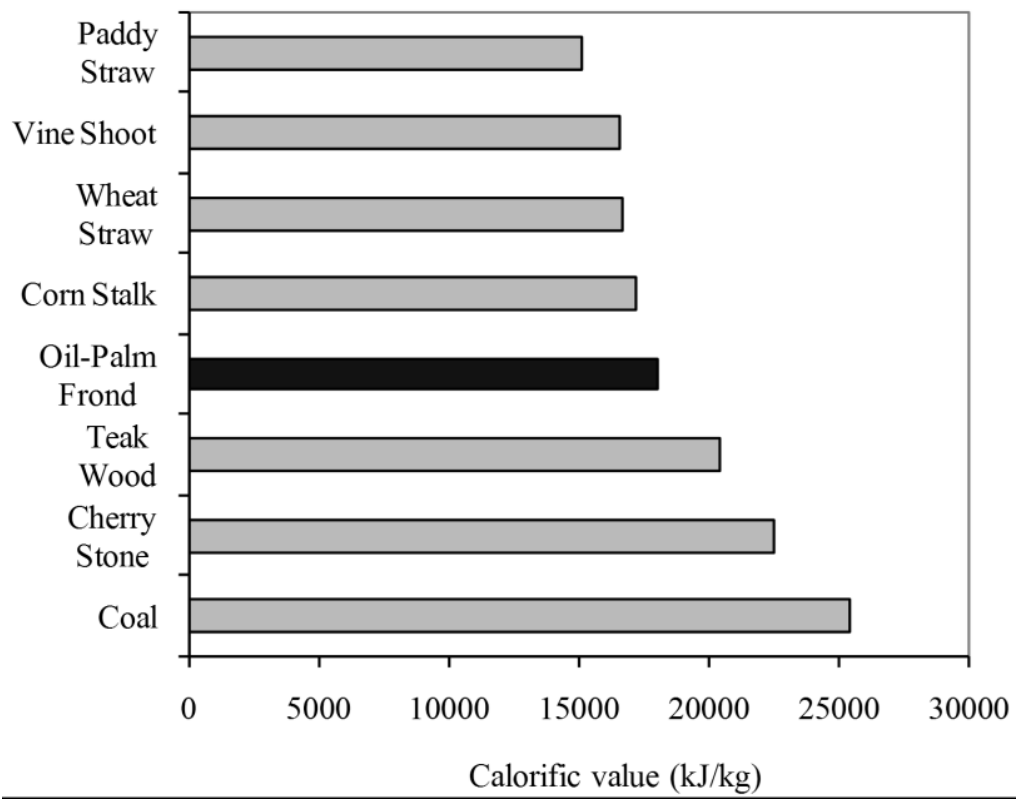

Figure 4. Calorific values of various biomass feeds.

\section{Energy Contents}

Measurements of the calorific value of the dry samples of OPF were repeated five times under the same conditions. The average calorific value of the oil palm fronds was $18,040 \mathrm{~kJ} / \mathrm{kg}$ and the standard deviation of less than $0.5 \%$. This was lower than that reported in a different work [50], in which the value was $22,868 \mathrm{~kJ} / \mathrm{kg}$. Shown in Figure 4 are the variations of calorific values for different biomass sources [47, 49] and coal for comparison with OPF. Obviously it is shown in the Figure that coal has the highest energy 
content. Nevertheless, in comparison with other biomass sources, the calorific value of OPF is shown to be competitive.

\section{Proximate Analysis}

The purpose of proximate analysis was for determination of the content of moisture, volatile matter, fixed carbon and ashes of the fronds. Three measurements were conducted. A typical proximate analysis result is shown in Figure 5, which is the weight loss characteristic of OPF as a function of temperature. The first reduction in weight during the test, i.e. between $90^{\circ} \mathrm{C}$ and $120^{\circ} \mathrm{C}$ represents the moisture content in the $\mathrm{OPF}$ samples. The reduction in weight was the highest at a temperature range of approximately between $120^{\circ} \mathrm{C}$ and $410^{\circ} \mathrm{C}$ during pyrolysis, causing release in the volatile matter contents. The ash content in the sample was obtained by measuring the remaining weight at the end of the experiment. The fixed carbon content was determined from the difference in the initial content of the sample and the content of ash, moisture and volatile matter.

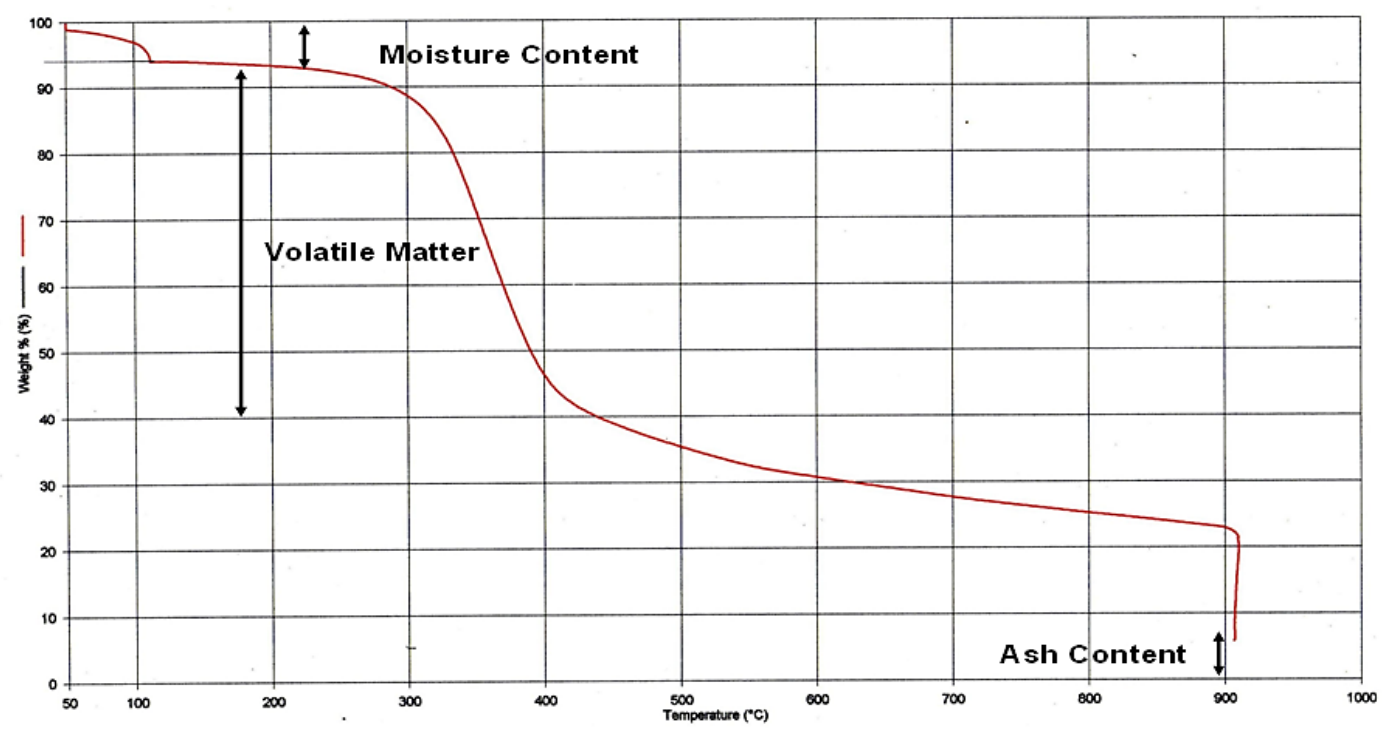

Figure 5. Variation of weight (\%) with temperature in proximate analysis test.

Table 2. Results of the proximate analysis test of OPF.

\begin{tabular}{lcccc}
\hline \multicolumn{5}{c}{ Composition (wt. \%) } \\
\hline & Moisture & Volatile matter & Fixed Carbon & Ash \\
\hline Average & 4 & 51 & 38 & 6 \\
\hline Std. Dev & 1.0 & 1.0 & 1.0 & 1.0 \\
\hline
\end{tabular}

The averaged proximate analysis results are shown in Table 2 . The average moisture content obtained from the proximate analysis is $4.0 \%$. In a similar work [50], the moisture content of the oil palm fronds was reported to be $7.2 \%$, although the test was done only once. Fuels with high moisture content (typically above $30 \%$ ) would be difficult to ignite. In addition, the calorific value of fuels with high moisture content would normally be reduced due to the need to evaporate the moisture before combustion can occur. With low moisture content, the OPF has a high potential to be practically used in gasification process. In comparison to other biomass, such as ground nut, cotton stalk 
and barley straw, the average volatile matter content for OPF (51\%) could be considered as moderate. High volatile matter content would favour high gas phase yields. The average ash content for OPF (6\%) was the lowest when compared with straw (8\%), sugar cane $(11 \%)$, cotton stalk (14\%), and rice husk (18\%). Ash content that is higher than $12 \%$ may cause the phenomena of slagging or clinkering [51]. Thus, the result indicates that the OPF can be used as a biomass feed in a gasification system with relatively less operational problems that may affect the overall efficiency, cost and performance.

\section{Ignitability of $\mathrm{OPF}$}

Shown in Figure 6 is the variation of the time to complete the combustion of approximately $70,000 \mathrm{~mm}^{3}$ of OPF with the use of various amount of gasoline and at different fan speeds. The circles, squares, triangles and diamonds represent the results at fan speeds of $0,50,100$, and 150 RPM respectively. The volume of gasoline was varies from 1 to $10 \mathrm{ml}$. Generally, it was observed that OPF was easy to ignite. As shown in Figure 6, the time taken to complete the combustion reduces as the fan speed is increased. The exact limit of the fan speed under which ignition would fail is unknown. Nevertheless, it was found from the experiment that under high turbulence at fan speeds of 100 and 150 RPM, the OPF failed to ignite. There was no problem to ignite the OPF when the fan was turned off. It is also shown in Figure 6 that the OPF burned faster when the quantity of gasoline was increased.

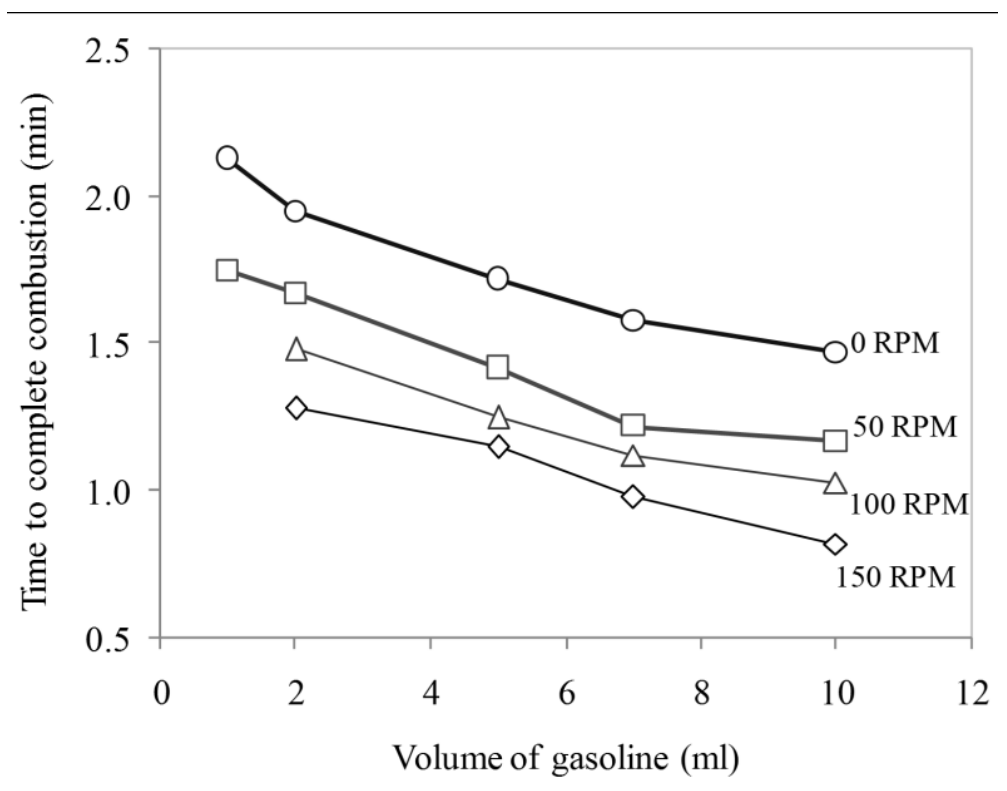

Figure 6. Typical variation of time to complete combustion with volume of gasoline for different fan speed.

\section{Flame of OPF Syngas}

In the qualitative study on the resulting flame of the OPF syngas, the fuel-air mix was concentrated to exit at a smaller exhaust pipe. The flame was self-ignited due to the high temperature flue and heat that were emitted from the combustion chamber. Shown in Figure 7 is a photograph of the flame of the syngas. The flame color, which was light blue, suggested that it was a clean flame. The flame appeared in burst detonation manner and was not stable. The sudden burst and disappearing flame suggested that the flow of gas through the exit was not uniform, therefore highlighting the need for a flow valve at 
the exhaust pipe to control the exhaust flow. This would maintain continuous gas combustion.

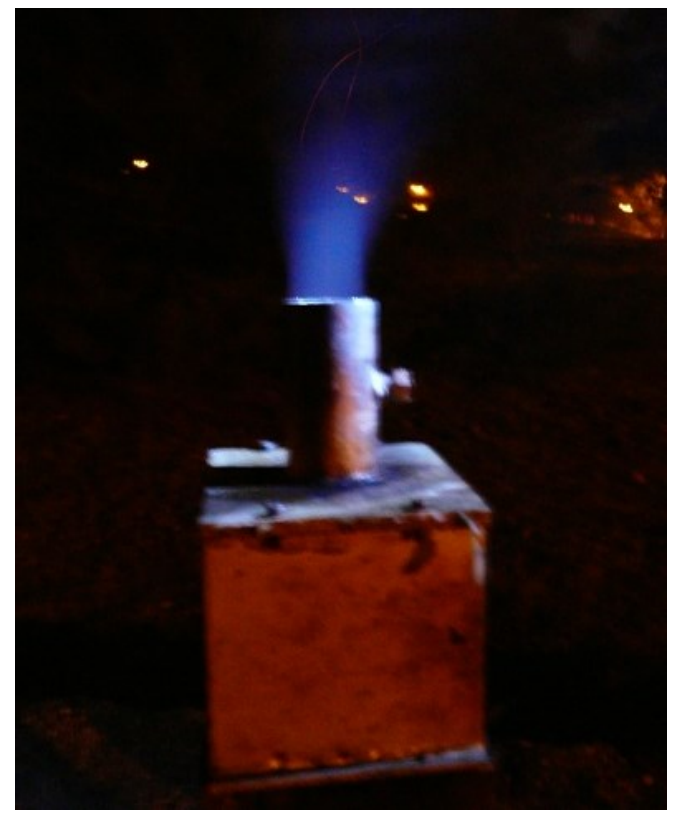

Figure 7. A flame of OPF syngas.

\section{Prediction of Syngas Composition}

Shown in Table 3 are the composition of the syngas from gasification of OPF using ASPEN PLUS and EES programs at oxidation temperatures of 700,1100 and $1500^{\circ} \mathrm{C}$. It is shown in the results that there are differences in the results of the two programs, particularly the trends for $\mathrm{CO}$ and $\mathrm{CO}_{2}$ with respect to the change in temperature. This was most probably caused by difference in the air flow rates, and also due to inaccuracy in EES as the nature of the feedstock was not taken into account [52]. It is shown in Table 3 that out of the four gases, $\mathrm{CO}$ and $\mathrm{CO}_{2}$ had the highest mass fractions, which were common for typical biomasses. From the results using ASPEN, it is shown that CO increases with the oxidation temperature; and vice versa for $\mathrm{CO}_{2}$ and $\mathrm{H}_{2} \cdot \mathrm{CH}_{4}$ had the lowest mass fractions, which was nearly negligible.

Table 3. Mass fractions of the OPF syngas at different oxidation temperature as predicted using ASPEN PLUS and EES programs.

\begin{tabular}{lcccc}
\hline \multirow{2}{*}{ Component } & \multirow{2}{*}{ Program } & \multicolumn{3}{c}{ Mass Fraction } \\
\cline { 3 - 5 } & & $700^{\circ} \mathrm{C}$ & $1100^{\circ} \mathrm{C}$ & $1500^{\circ} \mathrm{C}$ \\
\hline \multirow{2}{*}{$\mathrm{CO}$} & ASPEN & 0.190 & 0.239 & 0.260 \\
\cline { 2 - 5 } & EES & 0.148 & 0.127 & 0.039 \\
\multirow{2}{*}{$\mathrm{CO}_{2}$} & ASPEN & 0.231 & 0.157 & 0.125 \\
\hline \multirow{2}{*}{$\mathrm{H}_{2}$} & EES & 0.183 & 0.174 & 0.213 \\
\hline \multirow{2}{*}{$\mathrm{CH}_{4}$} & ASPEN & 0.014 & 0.012 & 0.010 \\
\cline { 2 - 5 } & EES & 0.188 & 0.077 & 0.011 \\
\hline
\end{tabular}


Shown in Table 4 is the comparison of mass fractions of syngas for various biomasses and charcoal [50, 52-56], for comparison with those of OPF. Also shown in the table are the values for $\mathrm{N}_{2}$. The $\mathrm{N}_{2}$ content is the highest for each of the fuels although generally the gas does not change much during gasification. It is shown in Table 4 that the CO contents for all biomasses are nearly the same; i.e. between 0.161 and 0.220 ; charcoal, due its nature (pyrolyzed), has a higher content of $\mathrm{CO}$. The similar trends in the contents of $\mathrm{H}_{2}$ and $\mathrm{CO}_{2}$ are also shown for all the biomasses. The content of $\mathrm{CH}_{4}$ is very small for most biomasses, although OPF is predicted to only have traces of the gas. The compositions of syngas produced from OPF were found to be satisfying enough for the use in dual-fuel internal combustion engine with diesel as the primary fuel $[55,56]$. The simulation results of the ASPEN model showed good trend of agreement with the syngas composition results of other biomasses. Compared to the actual results, averagely the ASPEN model showed up to $80-90 \%$ accurateness, which was sufficiently acceptable. Nevertheless, validation of the predictions with experimental data is required and will be performed in the future.

Table 4. Comparison of the predicted mass fractions of the syngas of OPF (at $900^{\circ} \mathrm{C}$ ) with those of other biomasses [5, 29-31] (obtained experimentally) at different oxidation temperatures.

\begin{tabular}{lccccc}
\hline Fuel & \multicolumn{5}{c}{ Mass Fraction } \\
\hline Charcoal & $\mathrm{CO}$ & $\mathrm{H}_{2}$ & $\mathrm{CH}_{4}$ & $\mathrm{CO}_{2}$ & $\mathrm{~N}_{2}$ \\
\hline Wood & 0.302 & 0.007 & 0.013 & 0.035 & 0.643 \\
\hline Wheat straw & 0.177 & 0.015 & 0.016 & 0.224 & 0.568 \\
\hline Coconut Husk & 0.161 & 0.015 & 0.013 & 0.224 & 0.588 \\
\hline Coconut Shell & 0.186 & 0.015 & 0.009 & 0.224 & 0.566 \\
\hline OPF & 0.205 & 0.009 & 0.012 & 0.219 & 0.555 \\
\hline
\end{tabular}

\section{CONCLUSIONS}

Experimental and simulation studies on the feasibility of oil palm fronds (OPF) for biomass gasification were performed in this work and it was generally found as a suitable form of biomass for gasification process. From the study, the followings can be concluded:

i) The ultimate and proximate analyses conducted on the OPF showed its suitability for gasification. The carbon content of OPF, about $43 \%$, was high and comparable with other types of biomass. Its low sulphur content (11\%) would result in less impact to the environment. The moisture content of OPF was found from the proximate analysis to be low (4-7\%). Its average volatile matter content (51\%) was moderate. The low content of ash for OPF (6\%) would minimize operational problems.

ii) The energy content of $(18,040 \mathrm{~kJ} / \mathrm{kg}$ or $4309 \mathrm{kcal} / \mathrm{kg})$ OPF was found to be comparable to other biomasses such as vine shoot, wheat straw, corn stalk and rice husk.

iii) OPF was found to be easy to ignite when burned with as low as one milliliter of gasoline as a starter fuel. It was also demonstrated that high fan speed could fail 
the ignition, and that it would probably be best to not have the lowest air velocity to start the flame.

iv) A qualitative study conducted on the flame of OPF syngas revealed that the flame was clean, as seen by its blue color. The flame was nevertheless unstable but could be resolved probably by adjusting the operating conditions such as by installing a flow valve at the exhaust pipe to control the exhaust flow.

v) Prediction of the composition of syngas using computer programs showed that the $\mathrm{CO}, \mathrm{H}_{2}$ and $\mathrm{CO}_{2}$ contents were nearly the same as for other biomasses like wood, wheat straw, coconut husk and coconut shell. Validation with experimental work is, however, required and would be conducted in the next research activity.

With these gathered information on OPF, it was concluded that OPF is suitable as a raw material for biomass solid fuel production for the use in thermal applications to generate heat and power, and is comparable with available biomass fuels in the consumer and industrial markets. However, further polishing of the processing techniques and the optimization of combustion and gasification are required in order to maximize the potentials of OPF as a solid fuel for small to medium scale heat and power producers. The possibility of converting OPF into fuel briquette and pellet is also another interesting area of study in making OPF a more convenient fuel for home and industrial users. As to promote and discover more of the potentials of OPF as a solid fuel for gasification and other solid fuel combustion applications, an actual usage in a pilot plant is highly recommended.

\section{ACKNOWLEDGEMENTS}

The authors would like to express their gratitude to Universiti Teknologi PETRONAS, Malaysia for their technical assistance and support in this work.

\section{REFERENCES}

[1] MPOB (Malaysian Palm Oil Board). Malaysian Palm oil industry performance 2008. Global Oils and Fats Business Magazine. 2009;6:1-4.

[2] Griffin WM, Michalek J, Matthews HS, Hassan MNA. Availability of biomass residues for co-firing in Peninsular Malaysia: Implications for cost and GHG emissions in the electricity sector. Energies. 2014;7:804-23.

[3] Wan Zahari M, Sato J, Furuichi S, Azizan A, Yunus M. Commercial processing of oil palm fronds feed in Malaysia. Forages and feed resources in commercial livestock production systems 8th Meeting of the Regional Working Group on Grazing and Feed Resources for Southeast Asia, Kuala Lumpur, Malaysia; 2003. p. 59-65.

[4] Chan K, Watson I, Lim K. Use of oil palm waste material for increased production. Planter. 1981;57:14-37.

[5] Konda R, Sulaiman SA, Ariwahjoedi B. Syngas production from gasification of oil palm fronds with an updraft gasifier. Journal of Applied Sciences. 2012;12:2555.

[6] Hassan OA, Ishida M, Shukri IM, Tajuddin ZA. Oil-palm fronds as a roughage feed source for ruminants in Malaysia: ASPAC, Food and Fertilizer Technology Center; 1996.

[7] MEC. Electricity supply industry in Malaysia: Performance and statistical information 2014. Putrajaya: Malaysia Energy Commission; 2015. 
[8] Alam SS, Omar NA, Ahmad MSB, Siddiquei H, Nor SM. Renewable Energy in Malaysia: Strategies and Development. Environmental Management and Sustainable Development. 2013;2:51.

[9] de Chazournes LB. Kyoto Protocol to the United Nations Framework Convention on Climate Change. UN's Audiovisual Library of International Law (http://untreaty un org/cod/avl/ha/kpccc/kpccc html). 1998.

[10] Muda N, Boosroh M. Gasification of coal-petcoke blends in a pilot scale gasification plant. International Journal of Automotive and Mechanical Engineering. 2013;8:1457-66.

[11] Gaqa S, Mamphweli S, Katwire D, Meyer E. The properties and suitability of various biomass/coal blends for co-gasification purposes. Journal of Sustainable Bioenergy Systems. 2014; 4:175-82.

[12] Lahijani P, Zainal ZA, Mohamed AR, Mohammadi M. Co-gasification of tire and biomass for enhancement of tire-char reactivity in $\mathrm{CO}_{2}$ gasification process. Bioresource Technology. 2013;138:124-30.

[13] Brar J, Singh K, Wang J, Kumar S. Cogasification of coal and biomass: a review. International Journal of Forestry Research. 2012; Article ID 363058, 1-10.

[14] Hagos FY, Aziz ARA, Sulaiman SA. Trends of syngas as a fuel in internal combustion engines. Advances in Mechanical Engineering. 2014;6:401587.

[15] Hagos FY, Aziz ARA, Sulaiman SA. Study of syngas combustion parameters effect on internal combustion engine. Asian Journal of Scientific Research. 2013;6:187.

[16] Bridgwater A. Thermal processing of biomass for fuels and chemicals. Renewable Bioenergy-Technologies, Risks and Rewards. 2003;3:33-61.

[17] Hassan M, Yacob S. Biomass utilization in Malaysia: Current status of conversion biomass into bioproducts. University Putra Malaysia, Malaysia; 2005.

[18] Jain A. Design parameters for a rice husk throatless gasifier reactor. International Commission of Agricultural Engineering, USA; 2006.

[19] Kobayashi N, Tanaka M, Piao G, Kobayashi J, Hatano S, Itaya Y, et al. High temperature air-blown woody biomass gasification model for the estimation of an entrained down-flow gasifier. Waste Management. 2009;29:245-51.

[20] Chong CN, Idrus AZ. Biomass energy potential in Malaysia. Asean Journal on Science and Technology for Development. 1998;5:15-27.

[21] Biaginia E, Barontiniab F, Tognottiab L. Gasification of agricultural residues in a demonstrative plant. Chemical Engineering. 2014;37.

[22] Begum S, Rasul MG, Akbar D, Ramzan N. Performance analysis of an integrated fixed bed gasifier model for different biomass feedstocks. Energies. 2013;6:650824.

[23] Thorson O, Wennberg O. Suitable drying processes and their integration with the gasification and DME-synthesis process. S.E.P. Scandinavian Energy Project AB, Report No. CHRISGAS August 2006 WP6 D43; 2006.

[24] Kumar A, Jones DD, Hanna MA. Thermochemical biomass gasification: a review of the current status of the technology. Energies. 2009;2:556-81.

[25] Lange S, Pellegrini L. Sustainable combined production of hydrogen and energy from biomass in Malaysia. Chemical Engineering Transaction. 2013;32:607-12.

[26] Shafie S, Mahlia T, Masjuki H, Ahmad-Yazid A. A review on electricity generation based on biomass residue in Malaysia. Renewable and Sustainable Energy Reviews. 2012;16:5879-89. 
[27] Nasrin A, Ma A, Chow M, Hamdan H, Choo Y. Blending of palm biomass and coal: an alternative fuel for power generation in Malaysia. Oil Palm Industry Economic Journal. 2006;6:31-6.

[28] Abas R, Kamaruddin M, Nordin A, Simeh M. A study on the Malaysian oil palm biomass sector - supply and perception of palm oil millers. Oil Palm Industry Economic Journal. 2011;11:28-41.

[29] Abdullah SS, Yusup S. Method for screening of Malaysian biomass based on aggregated matrix for hydrogen production through gasification. Journal of Applied Sciences(Faisalabad). 2010;10:3301-6.

[30] Sulaiman SA, Karim MF, Nazmi M, Moni Z, Atnaw SM. On gasification of different tropical plant-based biomass materials. Asian Journal of Scientific Research. 2013;6(2): 245-53.

[31] Moni M, Sulaiman SA. Downdraft gasification of oil palm frond: effects of temperature and operation time. Asian Journal of Scientific Research. 2012; 12: 2574-9.

[32] Sulaiman SA, Razali NHM, Konda RE, Atnaw SM, Moni MNZ. On Diversification of feedstock in gasification of oil palm fronds. Journal of Mechanical Engineering and Sciences. 2014; 6:907-15.

[33] Sulaiman S, Atnaw SM, Moni M. Experimental study on temperature profile of fixed-bed gasification of oil-palm fronds. International Journal of Technology. 2012;3:35-44.

[34] Moni M, Sulaiman S. Method of processing oil palm frond into biomass fuel for downdraft gasification. 3rd ICPER. Kuala Lumpur, Malaysia; 2012.

[35] Guangul FM. Gasification of oil palm fronds with preheated inlet air: Universiti Teknologi Petronas; 2013.

[36] Atnaw SM, Sulaiman SA, Yusup S. A simulation study of downdraft gasification of oil-palm fronds using ASPEN PLUS. Journal of Applied Sciences. 2011;11:1913-20.

[37] Atnaw SM, Sulaiman SA, Yusup S. Downdraft gasification of oil-palm fronds. Trends in Applied Sciences Research. 2011;6:1006.

[38] Moni MNZ, Sulaiman SA. Downdraft Gasification of Oil Palm Frond: Lambert Academic Publishing; 2012.

[39] Standard A. ASTM standards-D3176-89 standard practice for ultimate analysis of coal and coke. Annual book of ASTM standards, Section. 2002;5.

[40] Standard A. ASTM E1131-03 Standard test method for compositional analysis by thermogravimetry. West Conshohocken, PA: American Society for Testing and Materials; 2004.

[41] Standard A. A standard test method for gross calorific value of coal and coke. ASTM D5865. 2007.

[42] Fock F, Thomsen KP, Houbak N, Henriksen UB. Modelling a biomass gasification system by means of EES. SIMS 2000. 2000:179-86.

[43] Atnaw SM, Sulaiman SA. Modeling and simulation study of downdraft gasifier using oil-palm fronds. 3rd International Conference on Energy and Environment; 2009. p. 284-9.

[44] Zeeshan M, Arbab MN. Waste Heat Recovery and its Utilization for Electric Power Generation in Cement Industry. International Journal of Engineering and Technology. 2015;15.

[45] McKendry P. Energy production from biomass (part 3): gasification technologies. Bioresource Technology. 2002;83:55-63. 
[46] Turns SR. An introduction to combustion: McGraw-hill New York; 1996.

[47] Ganan J, Abdulla AA-K, Correa EC, Macías-García A. Energetic exploitation of vine shoot by gasification processes: a preliminary study. Fuel Processing Technology. 2006;87:891-7.

[48] Madhiyanon T, Lapirattanakun A, Sathitruangsak P, Soponronnarit S. A novel cyclonic fluidized-bed combustor ( $\psi$-FBC): Combustion and thermal efficiency, temperature distributions, combustion intensity, and emission of pollutants. Combustion and Flame. 2006;146:232-45.

[49] Shuangning X, Weiming Y, Li B. Flash pyrolysis of agricultural residues using a plasma heated laminar entrained flow reactor. Biomass and Bioenergy. 2005;29:135-41.

[50] Reed TB, Jantzen D. Generator Gas, The Swedish experience from 1939-1945. Solar Energy Research Institute, Colorado, USA; 1979.

[51] Gomes MdLI, Osório E, Vilela ACF. Thermal analysis evaluation of the reactivity of coal mixtures for injection in the blast furnace. Materials Research. 2006;9:915 .

[52] Moni M, Sulaiman SA. A preliminary study on synthesis gas produced by gasification of oil palm fronds. International Conference of Plant and Equipment Reliability Kuala Lumpur, Malaysia, 2010.

[53] Hoglund C. Agricultural residues as fuel for producer gas generation. The Beijer Institute, Stockholm, Sweden; 1981.

[54] Skov NA, Paperworth M. The pegasus unit. Pegasus Pub, Inc, Olympia, Washington, Mercury Press, Tacoma, Washington;1974.

[55] Mahgoub BK, Sulaiman S, Abdul Karim Z. Performance study of imitated syngas in a dual-fuel compression ignition diesel engine. International Journal of Automotive and Mechanical Engineering. 2015;11: 2282-93.

[56] Mahgoub B, Sulaiman S, Karim Z, Hagos F. Experimental study on the effect of varying syngas composition on the emissions of dual fuel $\mathrm{CI}$ engine operating at various engine speeds. IOP Conference Series: Materials Science and Engineering: IOP Publishing; 2015. p. 012006. 